\title{
Queilitis asociada a isotretinoína sistémica. Reporte de un caso
}

\author{
Cheilitis induced by systemic isotreinoin. Case Report
}

\section{Resumen}

Se presenta un caso de queilitis asociada a isotretinoína en individuo masculino bajo tratamiento de acné por vía sistémica. Aún descriptos por la literatura dermatológica los diferentes efectos colaterales de la administración de este fármaco a nivel mucocutáneo bucal (resecamiento e inflamación labial), en el plano odontológico los reportes son escasos, aún tratándose de una reacción de alta frecuencia ( $95 \%$ ) en pacientes sometidos a esta terapéutica. En la actualidad, con tratamientos cosméticos bajo supervisión del dermatólogo pero efectos bucales de larga persistencia (incluso con suspensión de la droga), el profesional odontólogo debe reconocer esta etiología medicamentosa y desarrollar las medidas adecuadas para la disminución o eliminación de estas afecciones.

\begin{abstract}
We present a case of cheilitis induced by isotreinoin in a male subject under systemic treatment for acne. The dermatologic literature has described its oral side effects (dry mouth and cheilitis) but odontologic reports are rare even when these reactions are frequently high (95\%). Today, knowing the cosmetic treatments are supervised by dermatologists with persistent oral side effects (including after drug treatment suspension), dentists need to recognize this medical aetiology and make the appropriated actions to reduce or eliminate these affections.
\end{abstract}

\section{Introducción}

La isotretinoína o ácido 13-cis-retinoico es una forma sintética de los denominados retinoides, compuestos cuya estructura y acción están relacionadas con la vitamina A o retinol y con una diversidad de acción biológica que incluye inmunomodulación, quimioprevención del cáncer, melanotropismo, estimulación del crecimiento, mantenimiento y diferenciación epitelial, morfogénesis, actividad antiinflamatoria y sebolítica, antagonismo de corticoesteroides, síntesis de la matriz dérmica y la estimulación de la angiogénesis. Estas propiedades han determinado un gran impacto en la Dermatología, con indicaciones en múltiples procesos: psoriasis, pitiriasis rubra pilaris, fotoenvejecimiento, genodermatosis ictiosiformes, cicatrices hipertróficas, rosácea, alteraciones de la queratinización mucosa, neoplasias incluyendo linfomas cutáneos, alopecias, cicatrización de heridas, alteraciones de la pigmentación, estrías de distensión, infecciones virales y alteraciones de la xerosis oftalmológica, mejorando sus tratamientos y pronósticos ${ }^{(1,2)}$.

La indicación más clásica y más antigua de los retinoides es el acné, enfermedad multifactorial de la unidad pilosebácea. Su clínica varía desde formas no inflamatorias mínimas hasta formas inflamatorias muy severas, que pueden incluso comprometer el estado general, como ocurre en el acné fulminans. Tiene una incidencia elevada y varios factores contribuyen a su patogénesis: hiperseborrea, diferenciación folicular anormal, aumento de la cronificación dérmica e hipercolonización bacteriana de la piel. Los factores nutricionales también pueden influir sobre algunos pacientes ${ }^{(3,4)}$.

La introducción de la Isotretinoína (Accutane ${ }^{\circledR}$, Roaccutane $\AA$, Derccutane $\left.{ }^{\circledR}\right)$ en los '80 revolucionó el tratamiento del acné disminuyendo el daño residual cosmético y psicológico. Inicialmente, su uso se limitaba

\section{Gabriel Mario Fonseca'}

Odontólogo. Facultad de Odontología de la Universidad Nacional de Córdoba, Argentina.

Director del Laboratorio de Pericias en Odontología Forense -LPO.

Facultad de Odontología, Universidad Nacional de Córdoba., Argentina.

Correspondencia:

Av. Haya de la Torre s/n, Ciudad Universitaria, Córdoba, Argentina (5000) Tel 54-351-4334274 int 141

gabriel_fonseca@argentina.com

Palabras clave: Dermatología Isotretinoína Queilitis Resecamiento Retinoides.

Key words: Dermatology Isotretinoin Cheilitis Dry Mouth Retinoids.

a los casos más severos de acné nódulo-quístico (aprobada en 1982 por la FDA para esta indicación) ${ }^{(1)}$, pero en los últimos años se ha indicado en diagnósticos de acné moderado que no responde a terapia convencional. $\mathrm{Si}$ bien puede ser utilizada en forma tópica (proporciona altas concentraciones terapéuticas con efectos adversos mínimos), la vía sistémica ha demostrado ser la forma más eficaz por ser el único fármaco con efecto sobre los cuatro principios patogénicos del acné: actúa sobre la glándula sebácea produciendo atrofia y disminuyendo hasta un $90 \%$ la producción de sebo, con acción en consecuencia antibacteriana, ya que impide el desarrollo de $P$. acnes que depende del glicerol resultante de la hidrólisis de los triglicéridos del sebo. También tiene acción antiinflamatoria y normaliza la queratinización folicular $^{(1-4)}$.

La dosis utilizada sistémicamente oscila en los $0,05 \mathrm{mg} / \mathrm{kg} /$ día, pero en todo caso es necesario conseguir 
una dosis total acumulada superior a $120 \mathrm{mg} / \mathrm{kg}$ para producir la remisión completa del acné Las dosis más bajas pueden ser eficaces, pero prolongan el tratamiento, y las recidivas son más rápidas y frecuentes; en el $40 \%$ de los casos es necesario repetirlo ${ }^{(1,3,4)}$. Se absorbe por vía digestiva y aumenta su disponibilidad cuando se ingiere con las comidas, en especial grasas. La concentración máxima se obtiene al cabo de $2-4 \mathrm{hs}^{(3)}$ y posee una vida media plasmática de 10 a 20 horas. No se almacena en tejido adiposo y se elimina por completo del organismo un mes después de la suspensión del medicamento ${ }^{(2)}$. Un tratamiento de 6 meses es suficiente para el $99 \%$ de los pacientes $^{(4)}$.

Se han notificado reacciones adversas de diferente frecuencia: trastornos mucocutáneos, afecciones osteomusculares, hipertrigliceridemia, niveles elevados de transaminasa hepática, sangrado rectal, afecciones oculares, trastornos psicológicos y neuroló$\operatorname{gicos}^{(2-4)}$. La isotretinoína es bien conocida también por su capacidad teratogénica; se ha hecho especial hincapié en asegurar que las mujeres en edad fértil bajo tratamiento no estén embarazadas o asuman las medidas anticonceptivas necesarias durante el mismo y hasta por lo menos un mes después de concluido ${ }^{(1,3,5,6)}$.

\section{Efectos colaterales bucales}

La toxicidad mucocutánea mencionada (epistaxis, sequedad, fotosensibilidad, alopecia) ha sido descripta como el efecto adverso más frecuente y pueden compararse a los de una hipervitaminosis A. Estos efectos (presentes hasta en un $97 \%$ de los pacientes) son generalmente tratables, dosisdependientes ${ }^{(2,3)}$. El resecamiento mucoso y la inflamación labial han sido mencionados por la literatura dermatológica como signos de alta frecuencia: $100 \%$ y $95 \%$ de los casos respectivamente ${ }^{(2-7)}$. Las queilitis aparecen de siete a diez días una vez iniciado el tratamiento y son consideradas marcadores clínicos de una buena absorción de la droga ${ }^{(2,7)}$. Se ha mencionado una probable participación de Staphylococcus aureus en queilitis angulares persistentes ${ }^{(8)}$. Se ha reportado también pérdida en la sensibilidad gustativa ${ }^{(9)}$.

\section{Caso clínico}

Paciente masculino de 23 años, asiste a la consulta por cuadro inflamatorio en mucosa y semimucosa labiales superiores e inferiores, de tipo descamativo con fondo eritematoso, presencia de grietas, sequedad, sensación de quemadura y edema (Figs. 1 y 2). Refiere haber iniciado hace 30 días tratamiento para acné con Roaccutan ${ }^{\circledR}$ cápsulas de $20 \mathrm{mg}$. en dosis de dos por día, para un peso de $110 \mathrm{~kg}$., la toma de las dos cápsulas juntas inmediatamente después de la cena. Las queilitis aparecieron concomitantes a otros síntomas (sangrado nasal y sequedad de piel) aproximadamente a los tres días de iniciado el tratamiento. Considerando la duración potencial del mismo (15 meses) y en vistas de estos efectos colaterales, el dermatólogo recomendó la colocación de manteca de cacao en labios y vaselina sólida en mucosa nasal, con controles mensuales. El paciente manifiesta sufrir agravamiento del cuadro cuando no realiza estas lubricaciones (situación imperante al momento de la consulta). No se describen ni se observan otros síntomas.

\section{Discusión}

El acné es una enfermedad que afecta a individuos de todas las razas y especialmente a adolescentes (70-87\% de los casos). Suele hacer regresión espontánea postpuberal, aunque en el $3 \%$ de los casos persiste hasta los 25 años o más. En el 15-30 \% de los casos es necesario tratamiento médico debido a la intensidad y/o persistencia de las lesiones ${ }^{(3,4)}$ y es en estos casos donde la Isotretinoína ha demostrado su gran efectividad farmacológica, aún con efectos adversos evaluados hasta 12 años después de suspendi$\mathrm{da}^{(2)}$. Encontramos que la literatura odontológica ha reportado escasamente su efecto sobre la mucosa oral y producción de queilitis, o un eventual manejo terapéutico de los síntomas ${ }^{(9-13)}$. Si bien los cuadros inflamatorios son inespecíficos y de morfología común, no debe descartarse la multiplicidad

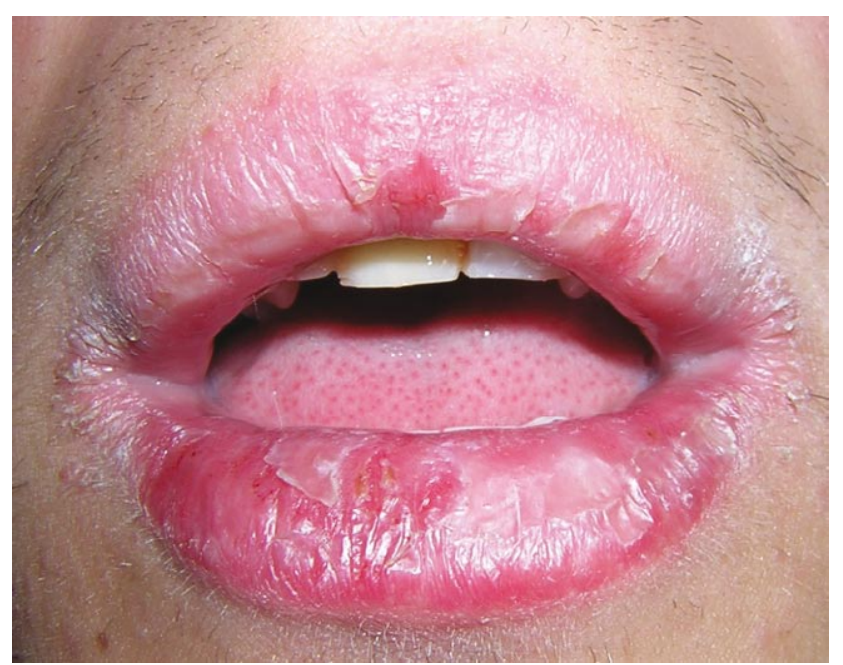

Figura 1

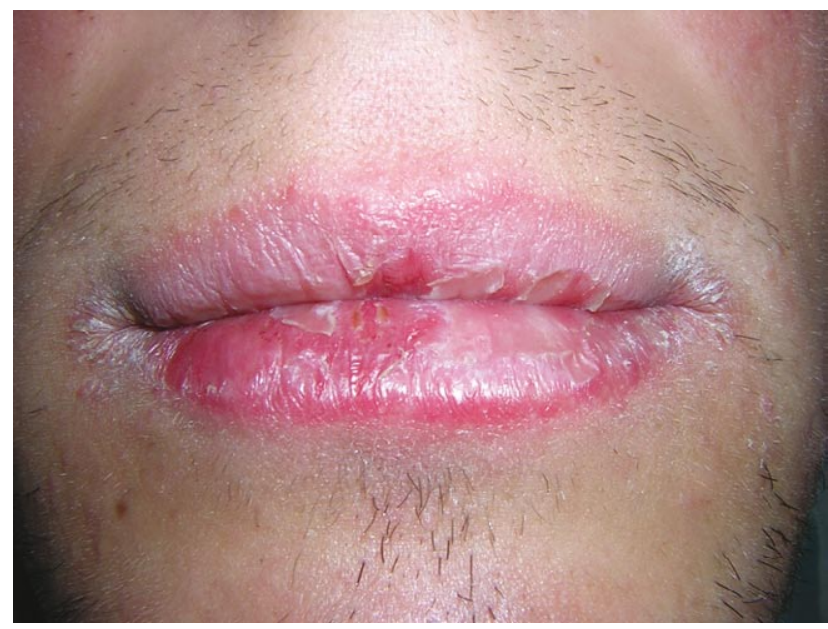

Figura 2 
de otros factores asociados a la acción del fármaco; se ha informado del agravamiento en exposiciones solares, abrasiones traumáticas o colonización bacteriana $^{(5,8)}$. La utilización de protectores solares con factor elevado (como mínimo factor de protección solar 15), evitar humedecer los labios con saliva y la asociación de antibióticos y corticoesteroides a los ya conocidos bálsamos y lubricantes labiales desde el mismo inicio del tratamiento, pueden controlar en forma absoluta estos síntomas $^{(2,5,8)}$. Según nuestra experiencia, es muy conveniente el hacer además control de queilofagias (hábito de morder el labio) para evitar abrasiones o trauma. Si bien se ha propuesto la vitamina E en altas dosis para disminuir los efectos adversos de la isotretinoína, estudios randomizados a doble ciego han concluido que esta asociación no mejora la incidencia, severidad o duración de los síntomas ${ }^{(1)}$. Iguales consideraciones podrían tenerse si la isotretinoína es utilizada en los ya conocidos tratamientos orales de leucoplasias $^{(1,14)}$ o líquen rojo plano ${ }^{(10,15)}$.

\section{Conclusiones}

Resecamiento e inflamación de mucosa y semimucosa de labios son manifestaciones de alta frecuencia en pacientes sometidos a tratamiento dermatológico de acne con isotretinoina por vía sistémica.

Esta toxicidad es tratable con simples pomadas lubricantes, pero se recomienda igualmente control de elementos físicos, químicos, traumá- ticos y biológicos que podrían estar agravando el cuadro.

Dado que esta manifestación no ha sido convenientemente descripta por la literatura odontológica, se recomienda una correcta anamnesis e interconsulta con el profesional dermatólogo para evaluar los elementos terapéuticos apropiados.

\section{Referencias bibliográficas}

1. Fernández Vozmediano JM, Armario Hita, JC. Retinoides en dermatología. Med Cutan Iber Lat Am 2003; 31(5):271294

2. Zegpi MS, Salomone C. Retinoides orales en niños y adolescentes. Rev Chilena Dermatol 2006; 22(1):32-36

3. Kaminsky A, Lago R. Tratamiento del acné. Dermatol Argent 2004; 10(3):171186

4. Zoubolis C, Piquero-Martin J. Update and Future of Systemic Acne Treatment. J Dermatology 2003; 206:37-53

5. Committee for Propietary Medicinal Products (CPMP). Summary information on a referral opinion following an arbitration pursant to article 30 of directive 2001/83/EC for Roaccutane and Associated Names. The European Agency for the Evaluation of Medicinal Products. Pre-authorisation Evaluation of Medicines for Human Use. London, 17 October 2003. Disponible en:

http: / / www.emea.europa.eu / pdfs/human/referral/roaccutane/ 284603en1.pdf).

6. White Gary. Atlas Levene de Dermatología. $3^{\circ}$ Ed Mosby Elsevier; 2004: 89
7. Orfanos CE, Zouboulis Ch C. Oral Retinoids in the Treatment of Seborrhoea and Acne. Dermatology 1998; 196:140147

8. Herane MI. Retinoides en Acné y rosácea. Folia Dermatol 1997;8(1):10-7

9. Scully C, Bagan J -V. Adverse Drug Reactions in the Orofacial Region. Crit Rev Oral Biol Med 2004;15(4):221-239

10. Regezi JA, Sciubba J. Patología Bucal. $2^{\circ}$ Ed México: Interamericana Mc GrawHill , 1995: 124-125

11. Abdollahi M, Radfar M. A review of Drug-Induced Oral Reactions. J Contemp Dent Pract 2003;(4)1:10-31

12. American Dental Association, Echeverría García JJ Terapéutica dental. Ed Masson Elsevier; 2003: 515

13. Laskaris George. Atlas de Enfermedades Orales. Ed. Masson; 2005: 94-95

14.Scardina GA, Carini F, Maresi E, Valenza V, Messina P. Evaluation of the clinical and histological effectiveness of isotretinoin in the therapy of oral leukoplakia: ten years of experience: is management still up to date and effective? Methods Find Exp Clin Pharmacol. 2006;28(2):115-9

15. Piattelli A, Carinci F, Iezzi G, Perrotti V, Goteri G, Fioroni M, et al. Oral lichen planus treated with 13-cisretinoic acid (isotretinoin): effects on the apoptotic process. Clin Oral Investig. 2007;11(3):283-8

Recibido :24-03-2008

Aceptado para publicación: 22-05-2008 